\title{
The Opposing Roles of Cellular Inhibitor of Apoptosis Proteins in Cancer
}

\author{
R. Lau and M. A. C. Pratt \\ Breast Cancer Research Lab, Department of Cellular and Molecular Medicine, University of Ottawa, 451 Smyth Road, \\ Ottawa, ON, Canada K1H 8 M5 \\ Correspondence should be addressed to M. A. C. Pratt, cpratt@uottawa.ca
}

Received 17 June 2012; Accepted 19 July 2012

Academic Editors: A. M. Garcia-Lora and F. Kuhnel

Copyright ( 2012 R. Lau and M. A. C. Pratt. This is an open access article distributed under the Creative Commons Attribution License, which permits unrestricted use, distribution, and reproduction in any medium, provided the original work is properly cited.

Cellular inhibitors of apoptosis proteins 1 and 2 (cIAP1/2) are members of the inhibitor of apoptosis protein (IAP) family that has been implicated in the pathology of human cancers due to their overexpression and function as blockers of cell death in various cancers. As a result, small molecule IAP antagonists have been developed and are currently under clinical evaluation for potential therapeutic use. In contrast, recent evidence has indicated a tumour-suppressing role for the cIAPs. Mutations in or loss of cIAPs have been identified as molecular lesions that contribute to constitutive activation of NF- $\kappa \mathrm{B}$ in hematopoietic malignancies. These studies reveal a context-dependent role for the cIAPs wherein both their overexpression and loss may contribute to tumourigenesis.

\section{Cellular Inhibitor of Apoptosis Proteins (cIAPs)}

The inhibitor of apoptosis proteins (IAPs) are potent suppressors of apoptosis and the human family is comprised of eight members: cellular IAP 1 (cIAP1), cellular IAP 2 (cIAP2), X-linked IAP (XIAP), neuronal apoptosis inhibitory protein (NAIP), melanoma IAP (ML-IAP), survivin, Apollon, and IAP like protein 2 (ILP2) [1]. All IAP proteins are characterized by the presence of one to three baculovirus IAP repeat (BIR) domains, which are zinc-binding regions of approximately 70 amino acids that mediate protein-protein interactions [2]. A number of IAPs also contain a RING (really interesting new gene) domain that confers ubiquitin protein ligase (E3) activity and are capable of auto-ubiquitination, as well as ubiquitination of proteins involved in apoptosis and signaling [3].

cIAP1 and cIAP2 can bind caspases, but do not directly inhibit them [4]. Instead, they exert their antiapoptotic effects through protein-protein interactions and by modulating the levels of other proteins through their function as ubiquitin ligases. Firstly, cIAP1/2 can bind to Smac and sequester it from XIAP, allowing XIAP to inhibit caspases and suppress apoptosis [5]. Furthermore, the cIAPs can target caspases and Smac for degradation by mediating their ubiquitination $[5,6]$. The ubiquitin ligase activity of the cIAPs is conferred by the presence of the RING domain in their carboxy terminus and their substrates include themselves and proteins involved in signaling [7], including multiple substrates in the tumour necrosis factor receptor (TNFR) complex $[8,9]$. This function imparts a role for cIAPs in the regulation of NF- $\kappa \mathrm{B}$ activation.

\section{Regulation of NF-kB by cIAPs}

Activation of NF- $\kappa \mathrm{B}$ signaling regulates a large number of genes involved in a wide range of biological functions including cytokines, adhesion molecules, chemokines, and a number of genes that contribute to survival by promoting proliferation and inhibiting apoptosis [10].

The cIAPs can regulate the canonical and noncanonical NF- $\kappa \mathrm{B}$ pathways in contrasting ways (Figure 1 ). cIAP $1 / 2$ plays a critical role in TNF receptor (TNFR) signaling to canonical NF- $\kappa$ B [11]. Binding of TNF- $\alpha$ to TNFR induces the formation of complex I, consisting of TRADD (TNF receptor-associated death domain), TRAF2 (TNF receptorassociated factor 2), and RIP1 (receptor interacting protein 1) $[12]$. TRAF2 recruits cIAP1/2 to the complex, where 


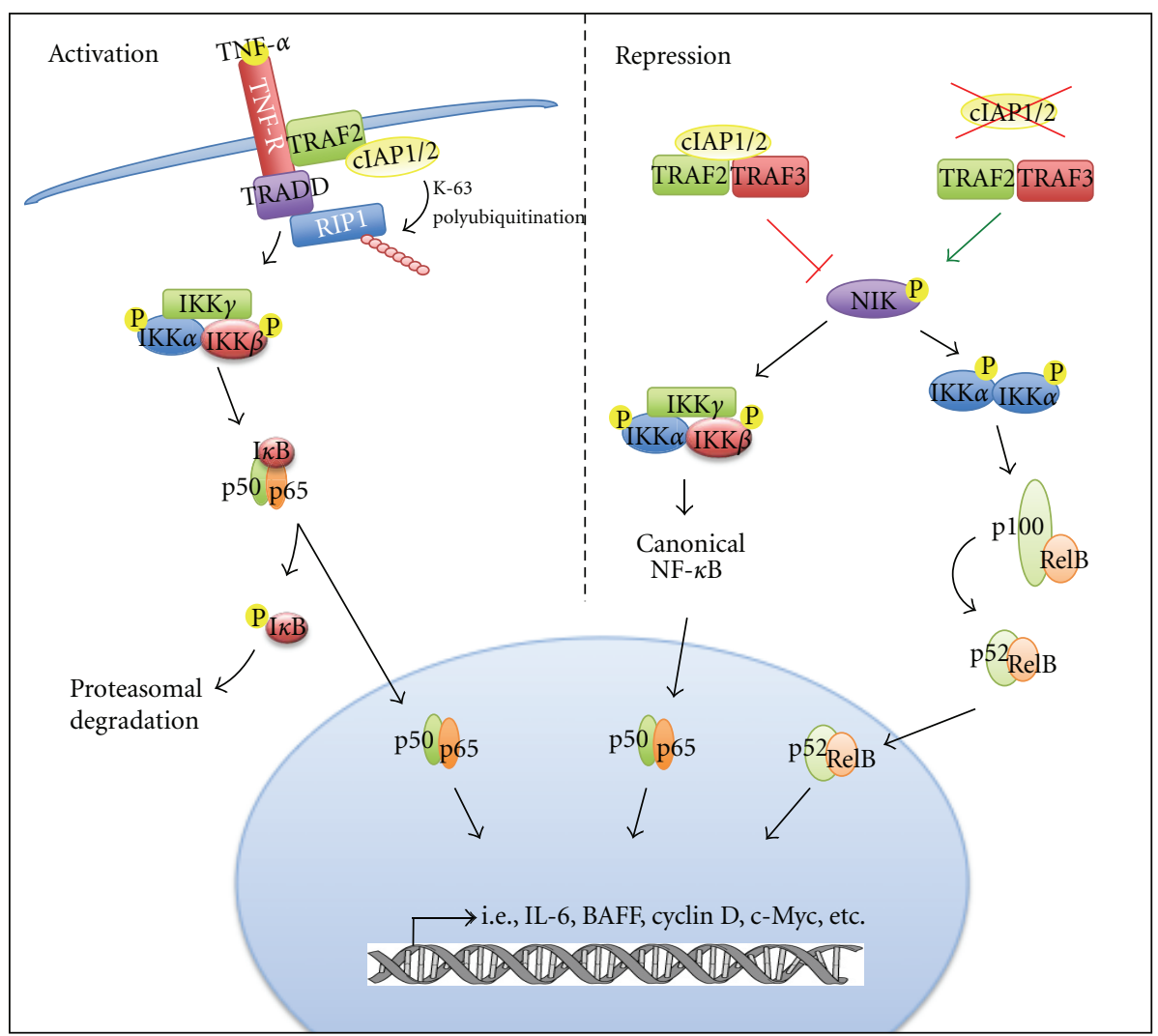

FIGURE 1: cIAP1/2 participates in positive and negative regulation of NF- $\kappa$ B. cIAP1/2 are recruited to an activated TNF receptor where they mediate K-63 polyubiquitination of RIP1. RIP1 subsequently activates the IKK complex, resulting in activation of canonical NF- $\kappa \mathrm{B}$ complexes. In contrast, cIAP1/2 represses activation of canonical and noncanonical NF- $\kappa$ B signaling by ubiquitinating NIK, leading to its degradation. Mutation or loss of cIAP1/2 results in accumulation of NIK, resulting in activation of both canonical and noncanonical NF- $\kappa \mathrm{B}$. Activated NF- $\kappa$ B complexes promote the transcription of various growth and survival factors, such as IL6 (Interleukin 6) and BAFF (B-cell activating factor). cIAP, cellular inhibitor of apoptosis; IKK, I $\kappa$ B kinase; NIK, NF- $\kappa$ B inducing kinase; RIP, receptor interacting protein; TNF, tumour necrosis factor; TNFR, TNF receptor; TRAF, TNFR-associated factor; TRADD, TNFR-associated death domain.

they are required for TNFR-induced activation of NF$\kappa \mathrm{B}$ signaling. The RING domains of cIAP1/2 catalyze the activating K63-linked polyubiquitination of RIP1, which activates the TAK1 (transforming growth factor- $\beta$-activated kinase 1) kinase complex [13]. This complex mediates the phosphorylation of IKK, which in turn phosphorylates $\mathrm{I} \kappa \mathrm{B}$ to signal its degradation and activates canonical NF$\kappa \mathrm{B}$ [14]. The K63-linked polyubiquitination of RIP1 also suppresses the activation of caspase- 8 and formation of the proapoptotic complex II [15], thereby preventing apoptosis. The expression of prosurvival genes stimulated by TNF- $\alpha$ activation of NF- $\kappa \mathrm{B}$ signaling is believed to play a major role in the protection against TNF- $\alpha$-induced cell death [16].

In contrast, cIAP $1 / 2$ can also repress NF- $\kappa \mathrm{B}$ activity. As previously mentioned, cIAP1/2 participate in a multisubunit ubiquitin ligase complex that includes TRAF2 and TRAF3. This complex targets NIK and tonically represses it to limit the activation of both the canonical and noncanonical NF- $\kappa$ B signaling [17-19]. Mutations in the constituents of this complex, including cIAP1/2, lead to constitutive activation of NF- $\kappa \mathrm{B}[20,21]$.

Thus, the cIAPs can both positively and negative regulate the NF- $\kappa$ B pathway. While cIAPs participate in the activating ubiquitination of RIP to result in activation of the canonical pathway in response to TNF/death ligands, they conversely ubiquitinate NIK in an inhibitory manner to suppress the both the canonical and noncanonical pathways.

\section{Oncogenic Role of cIAPs}

True to its name, the cIAPs play an important role in the inhibition of apoptosis. They are induced to promote survival during cellular stresses such as detachment from extracellular matrix [22] and ER stress [23]. They are also induced by prosurvival signaling such as nuclear factor (NF) $-\kappa \mathrm{B}[24,25]$. Not surprisingly, their antiapoptotic activity is exploited for tumour cell survival, and their expression is induced by potent oncogenes such as Ras [26] and E6 [27]. Many members of the IAP family, including the cIAPs, are overexpressed in a number of human cancers and are associated with poor prognosis [28]. Direct genetic evidence has demonstrated the cIAPs as protooncogenes. Chromosomal amplification of the 11q21-23 region, which encompasses both cIAP1 and cIAP2, is observed in a variety of cancers, including renal cell carcinomas, glioblastomas, gastric carcinomas, and nonsmall cell lung carcinomas [29-31]. Additional genetic 
evidence comes from MALT (mucosa-associated lymphoid tissue) lymphoma. Approximately $50 \%$ of surveyed cases displayed a $t(11,18)(\mathrm{q} 21 ; \mathrm{q} 21)$ translocation, which results in a fusion of the BIR domains of cIAP2 with the carboxy terminus of the paracaspase domain of MALT1 $[32,33]$. The resulting fusion protein promotes constitutive activation of $\mathrm{NF}-\kappa \mathrm{B}$, leading to increased prosurvival signaling.

3.1. IAP Antagonists. The anti-apoptotic function of IAPs and their overexpression in a wide variety of cancers make them attractive therapeutic targets. As such, a number of strategies to target IAP proteins in cancer are currently under investigation. One focus has been on the generation of molecules that mimic the aminoterminus of mature Smac. These Smac mimetics disrupt IAP : caspase and IAP : SMAC interactions and can stimulate cell death [34]. Originally designed to target XIAP, these antagonists exhibit higher affinities for the cIAPs, triggering autoubiquitination and proteasomal degradation. Following treatment with an IAP antagonist, it is speculated that the downregulation of cIAPs result in the accumulation of NIK, which activates noncanonical NF- $\kappa \mathrm{B}$ signaling and leads to autocrine TNF$\alpha$ production [35-37]. In the absence of cIAPs, activation of survival genes by p65/RelA is greatly reduced $[14,38]$. TNF- $\alpha$ instead triggers the formation of the pro-apoptotic complex II, consisting of FADD, caspase-8, and deubiquitinated RIP1, resulting in apoptosis [39]. While treatment with IAP antagonists as a single agent has shown some success in a limited number of human cancer cell lines, their cytotoxicity is often augmented when used in combination with other agents such as TNF- $\alpha$ and tumour necrosis factor-related apoptosis-inducing ligand (TRAIL) [30, 40].

\section{Tumour Suppressing Role of cIAPs}

While overexpression of cIAPs likely promote tumourigenesis by inhibiting apoptosis through their interactions with components of the apoptotic machinery (i.e., SMAC/DIABLO), the loss of cIAPs in a number of blood malignancies is associated with pro-survival activation of NF- $\kappa$ B signaling. Recent studies have shown that mutations or translocations resulting in the loss of cIAPs are, in part, responsible for constitutive activation of NF- $\kappa \mathrm{B}$ signaling in several cancers. Two independent groups reported that constitutive activation of NF- $\kappa \mathrm{B}$ signaling in multiple myeloma may be attributable to alterations in cIAP2 or components of the NIK-regulating complex including cIAP1, TRAF2, and/or TRAF3 [20, 21]. The resulting NIK-mediated activation of both canonical and noncanonical NF- $\kappa \mathrm{B}$ signaling is essential for promoting tumour cell survival in multiple myeloma [20]. Aberrant activation of NF- $\kappa \mathrm{B}$ is also detected in a majority $(\sim 60 \%)$ of splenic marginal zone lymphomas (SMZL) [41]. Investigation into possible molecular lesions in the NF- $\kappa \mathrm{B}$ pathway revealed disruption of cIAP2 as a contributor to constitutive NF- $\kappa \mathrm{B}$ activation. Out of 101 SMZL cases analyzed, $11 \%$ of cases harboured abnormalities in cIAP2 by inactivating mutations, missense mutations and gene deletions. These mutations were all monoallelic, suggesting that genetic lesions in cIAP2 may have a dominant negative effect. All of the SMZL primary cases displaying cIAP2 mutations showed constitutive activation of NF- $\kappa \mathrm{B}$ signaling, including accumulation of NIK.

Rossi et al. recently showed that genetic disruption of cIAP2 in chronic lymphocytic leukemia is associated with fludarabine resistance and a poor outcome similar to that attributed to TP53 abnormalities [42]. Additionally, progressive but fludarabine-sensitive disease was devoid of cIAP2 mutations/loss, indicating that the genetic lesions are specifically associated with a chemoresistant phenotype. The loss of cIAP2 in these lesions was found to be associated with constitutive activation of NF- $\kappa \mathrm{B}$, consistent with its role as a negative regulator of NIK. Interestingly, disruption of cIAP2 through inactivating mutations and/or gene deletions was found to be mutually exclusive with TP53 abnormalities.

Since NF- $\kappa$ B is a known negative regulator of p53 [43], it is possible that the loss of cIAP2 in these cells results in reduced p53 function, thus obviating the requirement for inactivating mutations in TP53. In line with this, our lab has shown that in breast mammary epithelial cells, the downregulation of cIAP2 results in reduction of wild-type p53 protein (unpublished data). This may also explain why CLL patients lacking functional cIAP2 display a similar outcome as patients with TP53 abnormalities.

\section{Conclusion}

Transient activation of NF- $\kappa$ B signaling is utilized by normal B-lymphocytes to promote cell survival and differentiation as a response to antigens [44]. However, aberrant activation of NF- $\kappa \mathrm{B}$ is a major contributor to the oncogenesis [45]. The loss of cIAPs in a number of lymphoid malignancies results in constitutive activation of both canonical and noncanonical NF- $\kappa$ B signaling, leading to increased survival and proliferative signals. In contrast to the oncogenic role typically attributed to IAPs, these recent studies have shown a tumour-suppressing role for the cIAPs in limiting NF$\kappa \mathrm{B}$ activity. These studies underscore the importance of the cellular context under which cIAPs are therapeutically targeted since overexpression and loss can both contribute to cancer cell progression.

\section{References}

[1] G. S. Salvesen and C. S. Duckett, "IAP proteins: blocking the road to death's door," Nature Reviews Molecular Cell Biology, vol. 3, no. 6, pp. 401-410, 2002.

[2] M. G. Hinds, R. S. Norton, D. L. Vaux, and C. L. Day, "Solution structure of a baculoviral inhibitor of apoptosis (IAP) repeat," Nature Structural Biology, vol. 6, no. 7, pp. 648-651, 1999.

[3] S. M. Srinivasula and J. D. Ashwell, "IAPs: what's in a name?" Molecular Cell, vol. 30, no. 2, pp. 123-135, 2008.

[4] B. P. Eckelman and G. S. Salvesen, "The human anti-apoptotic proteins cIAP1 and cIAP2 bind but do not inhibit caspases," Journal of Biological Chemistry, vol. 281, no. 6, pp. 3254-3260, 2006.

[5] S. Hu and X. Yang, "Cellular inhibitor of apoptosis 1 and 2 are ubiquitin ligases for the apoptosis inducer Smac/DIABLO," Journal of Biological Chemistry, vol. 278, no. 12, pp. 1005510060, 2003. 
[6] Y. E. Choi, M. Butterworth, S. Malladi, C. S. Duckett, G. M. Cohen, and S. B. Bratton, "The E3 ubiquitin ligase cIAP1 binds and ubiquitinates caspase- 3 and -7 via unique mechanisms at distinct steps in their processing," Journal of Biological Chemistry, vol. 284, no. 19, pp. 12772-12782, 2009.

[7] D. L. Vaux and J. Silke, "IAPs, RINGs and ubiquitylation," Nature Reviews Molecular Cell Biology, vol. 6, no. 4, pp. 287297, 2005.

[8] M. J. M. Bertrand, S. Milutinovic, K. M. Dickson et al., "cIAP1 and cIAP2 facilitate cancer cell survival by functioning as E3 ligases that promote RIP1 ubiquitination," Molecular Cell, vol. 30, no. 6, pp. 689-700, 2008.

[9] T. Samuel, K. Welsh, T. Lober, S. H. Togo, J. M. Zapata, and J. C. Reed, "Distinct BIR domains of cIAP1 mediate binding to and ubiquitination of tumor necrosis factor receptorassociated factor 2 and second mitochondrial activator of caspases," Journal of Biological Chemistry, vol. 281, no. 2, pp. 1080-1090, 2006.

[10] M. Karin, Y. Cao, F. R. Greten, and Z. W. Li, "NF- $\kappa$ B in cancer: from innocent bystander to major culprit," Nature Reviews Cancer, vol. 2, no. 4, pp. 301-310, 2002.

[11] M. Rothe, M. G. Pan, W. J. Henzel, T. M. Ayres, and D. V. Goeddel, "The TNFR2-TRAF signaling complex contains two novel proteins related to baculoviral inhibitor of apoptosis proteins," Cell, vol. 83, no. 7, pp. 1243-1252, 1995.

[12] H. Hsu, J. Xiong, and D. V. Goeddel, "The TNF receptor 1 -associated protein TRADD signals cell death and NF- $\kappa \mathrm{B}$ activation," Cell, vol. 81, no. 4, pp. 495-504, 1995.

[13] C. Wang, L. Deng, M. Hong, G. R. Akkaraju, J. I. Inoue, and Z. J. Chen, "TAK1 is a ubiquitin-dependent kinase of MKK and IKK," Nature, vol. 412, no. 6844, pp. 346-351, 2001.

[14] E. Varfolomeev, T. Goncharov, A. V. Fedorova et al., "c-IAP1 and c-IAP2 are critical mediators of tumor necrosis factor $\alpha(\mathrm{TNF} \alpha)$-induced NF- $\kappa \mathrm{B}$ activation," Journal of Biological Chemistry, vol. 283, no. 36, pp. 24295-24299, 2008.

[15] C. Y. Wang, M. W. Mayo, R. G. Korneluk, D. V. Goeddel, and A. S. Baldwin, "NF- $\simeq$ B antiapoptosis: induction of TRAF1 and TRAF2 and c-IAP1 and c- IAP2 to suppress caspase- 8 activation," Science, vol. 281, no. 5383, pp. 1680-1683, 1998.

[16] M. Karin and A. Lin, "NF- $\kappa$ B at the crossroads of life and death," Nature Immunology, vol. 3, no. 3, pp. 221-227, 2002.

[17] G. Liao, M. Zhang, E. W. Harhaj, and S. C. Sun, "Regulation of the NF- $\kappa$ B-inducing kinase by tumor necrosis factor receptorassociated factor 3-induced degradation," Journal of Biological Chemistry, vol. 279, no. 25, pp. 26243-26250, 2004.

[18] B. J. Zarnegar, Y. Wang, D. J. Mahoney et al., "Noncanonical NF- $\kappa \mathrm{B}$ activation requires coordinated assembly of a regulatory complex of the adaptors cIAP1, cIAP2, TRAF2 and TRAF3 and the kinase NIK," Nature Immunology, vol. 9, no. 12, pp. 1371-1378, 2008.

[19] S. Vallabhapurapu, A. Matsuzawa, W. Z. Zhang et al., "Nonredundant and complementary functions of TRAF2 and TRAF3 in a ubiquitination cascade that activates NIK-dependent alternative NF- $\kappa \mathrm{B}$ signaling," Nature Immunology, vol. 9, no. 12, pp. 1364-1370, 2008.

[20] C. M. Annunziata, R. E. Davis, Y. Demchenko et al., "Frequent engagement of the classical and alternative NF- $\kappa \mathrm{B}$ pathways by diverse genetic abnormalities in multiple myeloma," Cancer Cell, vol. 12, no. 2, pp. 115-130, 2007.

[21] J. J. Keats, R. Fonseca, M. Chesi et al., "Promiscuous mutations activate the noncanonical NF- $\kappa \mathrm{B}$ pathway in multiple myeloma," Cancer Cell, vol. 12, no. 2, pp. 131-144, 2007.
[22] Z. Liu, H. Li, X. Wu et al., "Detachment-induced upregulation of XIAP and cIAP2 delays anoikis of intestinal epithelial cells," Oncogene, vol. 25, no. 59, pp. 7680-7690, 2006.

[23] R. B. Hamanaka, E. Bobrovnikova-Marjon, X. Ji, S. A. Liebhaber, and J. A. Diehl, "PERK-dependent regulation of IAP translation during ER stress," Oncogene, vol. 28, no. 6, pp. 910-920, 2009.

[24] Z. L. Chu, T. A. McKinsey, L. Liu, J. J. Gentry, M. H. Malim, and D. W. Ballard, "Suppression of tumor necrosis factor-induced cell death by inhibitor of apoptosis c-IAP2 is under NF- $\kappa \mathrm{B}$ control," Proceedings of the National Academy of Sciences of the United States of America, vol. 94, no. 19, pp. 10057-10062, 1997.

[25] S. Y. Hong, W. H. Yoon, J. H. Park, S. G. Kang, J. H. Ahn, and T. H. Lee, "Involvement of two NF- $\kappa \mathrm{B}$ binding elements in tumor necrosis factor $\alpha$-, CD40-, and Epstein-Barr virus latent membrane protein 1-mediated induction of the cellular inhibitor of apoptosis protein 2 gene," Journal of Biological Chemistry, vol. 275, no. 24, pp. 18022-18028, 2000.

[26] Z. Liu, H. Li, M. Derouet et al., "ras oncogene triggers up-regulation of cIAP2 and XIAP in intestinal epithelial cells: epidermal growth factor receptor-dependent and independent mechanisms of ras-induced transformation," Journal of Biological Chemistry, vol. 280, no. 45, pp. 3738337392, 2005

[27] H. H. Wu, J. Y. Wu, Y. W. Cheng et al., "cIAP2 upregulated by E6 oncoprotein via epidermal growth factor receptor/phosphatidylinositol 3-kinase/AKT pathway confers resistance to cisplatin in human papillomavirus 16/18-infected lung cancer," Clinical Cancer Research, vol. 16, no. 21, pp. 5200-5210, 2010.

[28] C. W. Wright and C. S. Duckett, "Reawakening the cellular death program in neoplasia through the therapeutic blockade of IAP function," Journal of Clinical Investigation, vol. 115, no. 10, pp. 2673-2678, 2005.

[29] Z. Dai, W. G. Zhu, C. D. Morrison et al., "A comprehensive search for DNA amplification in lung cancer identifies inhibitors of apoptosis cIAP1 and cIAP2 as candidate oncogenes," Human Molecular Genetics, vol. 12, no. 7, pp. 791-801, 2003.

[30] E. C. LaCasse, D. J. Mahoney, H. H. Cheung, S. Plenchette, S. Baird, and R. G. Korneluk, "IAP-targeted therapies for cancer," Oncogene, vol. 27, no. 48, pp. 6252-6275, 2008.

[31] I. Imoto, Z. Q. Yang, A. Pimkhaokham et al., "Identification of cIAP1 as a candidate target gene within an amplicon at $11 \mathrm{q} 22$ in esophageal squamous cell carcinomas," Cancer Research, vol. 61, no. 18, pp. 6629-6634, 2001.

[32] T. Akagi, M. Motegi, A. Tamura et al., "A novel gene, MALT1 at $18 \mathrm{q} 21$, is involved in $\mathrm{t}(11 ; 18)(\mathrm{q} 21 ; \mathrm{q} 21)$ found in low-grade B-cell lymphoma of mucosa-associated lymphoid tissue," Oncogene, vol. 18, no. 42, pp. 5785-5794, 1999.

[33] J. Dierlamm, M. Baens, I. Wlodarska et al., "The apoptosis inhibitor gene API2 and a novel 18q gene, MLT, are recurrently rearranged in the $\mathrm{t}(11 ; 18)(\mathrm{q} 21 ; \mathrm{q} 21)$ associated with mucosaassociated lymphoid tissue lymphomas," Blood, vol. 93, no. 11, pp. 3601-3609, 1999.

[34] D. Vucic and W. J. Fairbrother, "The inhibitor of apoptosis proteins as therapeutic targets in cancer," Clinical Cancer Research, vol. 13, no. 20, pp. 5995-6000, 2007.

[35] E. Varfolomeev, J. W. Blankenship, S. M. Wayson et al., "IAP Antagonists Induce Autoubiquitination of c-IAPs, NF$\kappa \mathrm{B}$ Activation, and TNF $\alpha$-Dependent Apoptosis," Cell, vol. 131, no. 4, pp. 669-681, 2007. 
[36] J. E. Vince, W. W. L. Wong, N. Khan et al., "IAP antagonists target cIAP1 to induce TNF $\alpha$-dependent apoptosis," Cell, vol. 131, no. 4, pp. 682-693, 2007.

[37] S. L. Petersen, L. Wang, A. Yalcin-Chin et al., "Autocrine TNF $\alpha$ signaling renders human cancer cells susceptible to smacmimetic-induced apoptosis," Cancer Cell, vol. 12, no. 5, pp. 445-456, 2007.

[38] D. J. Mahoney, H. H. Cheung, R. Lejmi Mrad et al., "Both cIAP1 and cIAP2 regulate TNF $\alpha$-mediated NF- $\kappa$ B activation," Proceedings of the National Academy of Sciences of the United States of America, vol. 105, no. 33, pp. 11778-11783, 2008.

[39] L. Wang, F. Du, and X. Wang, "TNF- $\alpha$ induces two distinct caspase- 8 activation pathways," Cell, vol. 133, no. 4, pp. 693703, 2008.

[40] H. H. Cheung, D. J. Mahoney, E. C. LaCasse, and R. G. Korneluk, "Down-regulation of c-FLIP enhances death of cancer cells by Smac mimetic compound," Cancer Research, vol. 69, no. 19, pp. 7729-7738, 2009.

[41] D. Rossi, S. Deaglio, D. Dominguez-Sola et al., "Alteration of BIRC3 and multiple other NF-kappaB pathway genes in splenic marginal zone lymphoma," Blood, vol. 118, no. 18, pp. 4930-4934, 2011.

[42] D. Rossi, M. Fangazio, S. Rasi et al., "Disruption of BIRC3 associates with fludarabine chemorefractoriness in TP53 wildtype chronic lymphocytic leukemia," Blood, vol. 119, no. 12, pp. 2854-2862, 2012.

[43] V. Tergaonkar, M. Pando, O. Vafa, G. Wahl, and I. Verma, "p53 stabilization is decreased upon NF $\kappa$ B activation: a role for NF $\kappa$ B in acquisition of resistance to chemotherapy," Cancer Cell, vol. 1, no. 5, pp. 493-503, 2002.

[44] U. Siebenlist, K. Brown, and E. Claudio, "Control of lymphocyte development by nuclear factor-kB," Nature Reviews Immunology, vol. 5, no. 6, pp. 435-445, 2005.

[45] D. S. Bassères and A. S. Baldwin, "Nuclear factor- $\kappa B$ and inhibitor of $\kappa \mathrm{B}$ kinase pathways in oncogenic initiation and progression," Oncogene, vol. 25, no. 51, pp. 6817-6830, 2006. 


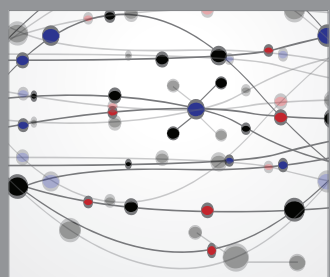

The Scientific World Journal
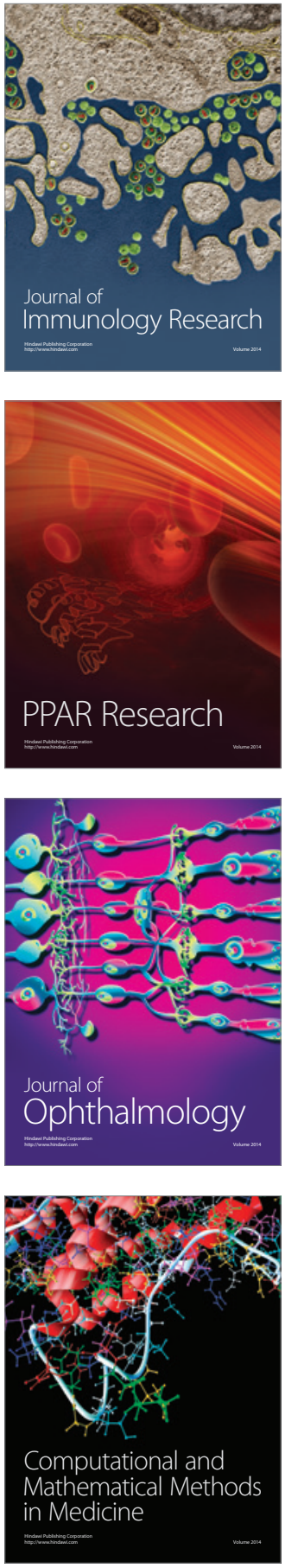

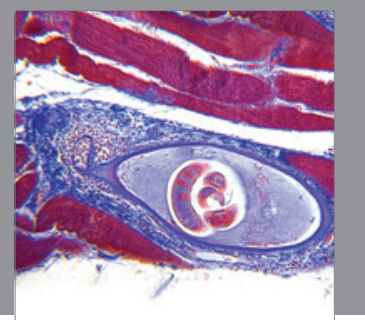

Gastroenterology

Research and Practice
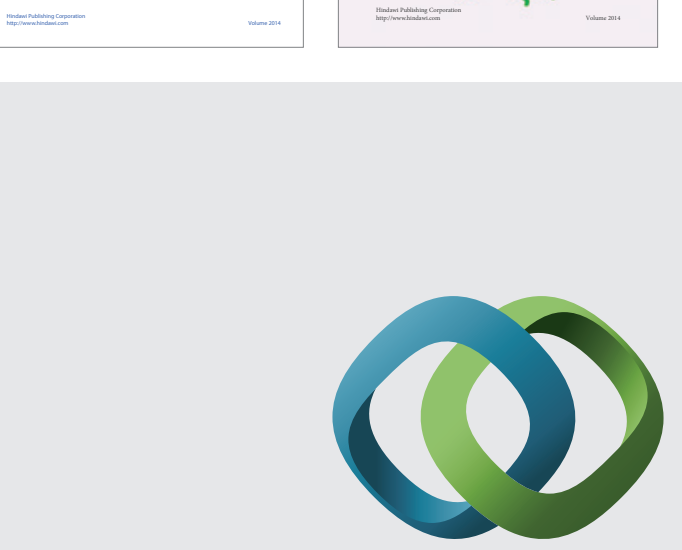

\section{Hindawi}

Submit your manuscripts at

http://www.hindawi.com
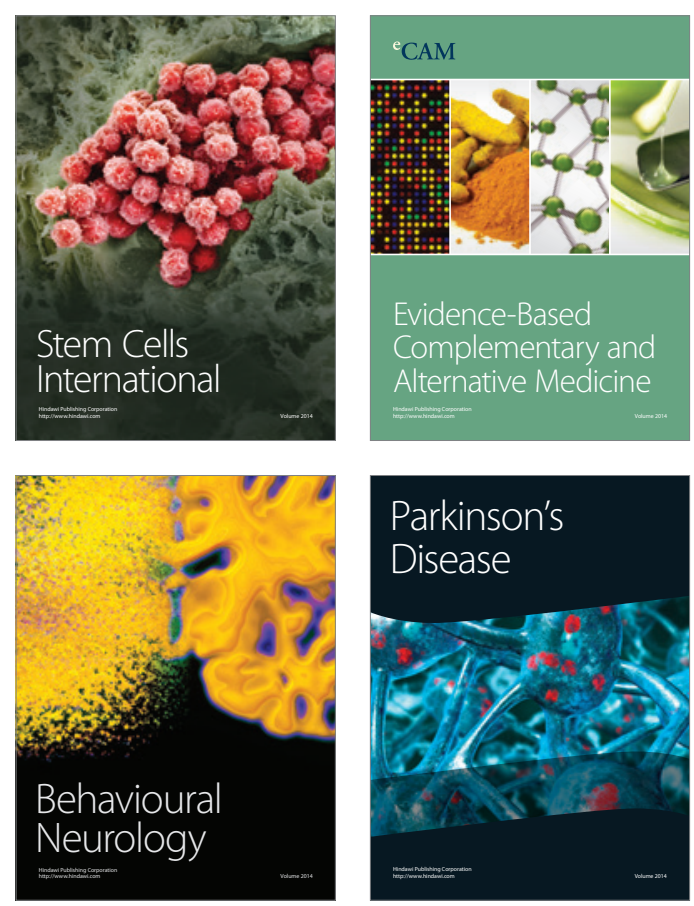

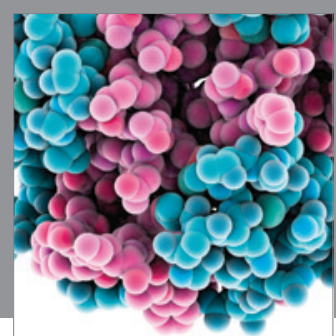

Journal of
Diabetes Research

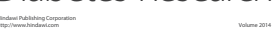

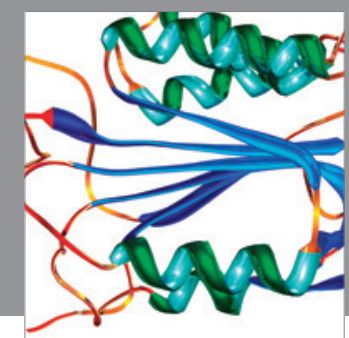

Disease Markers
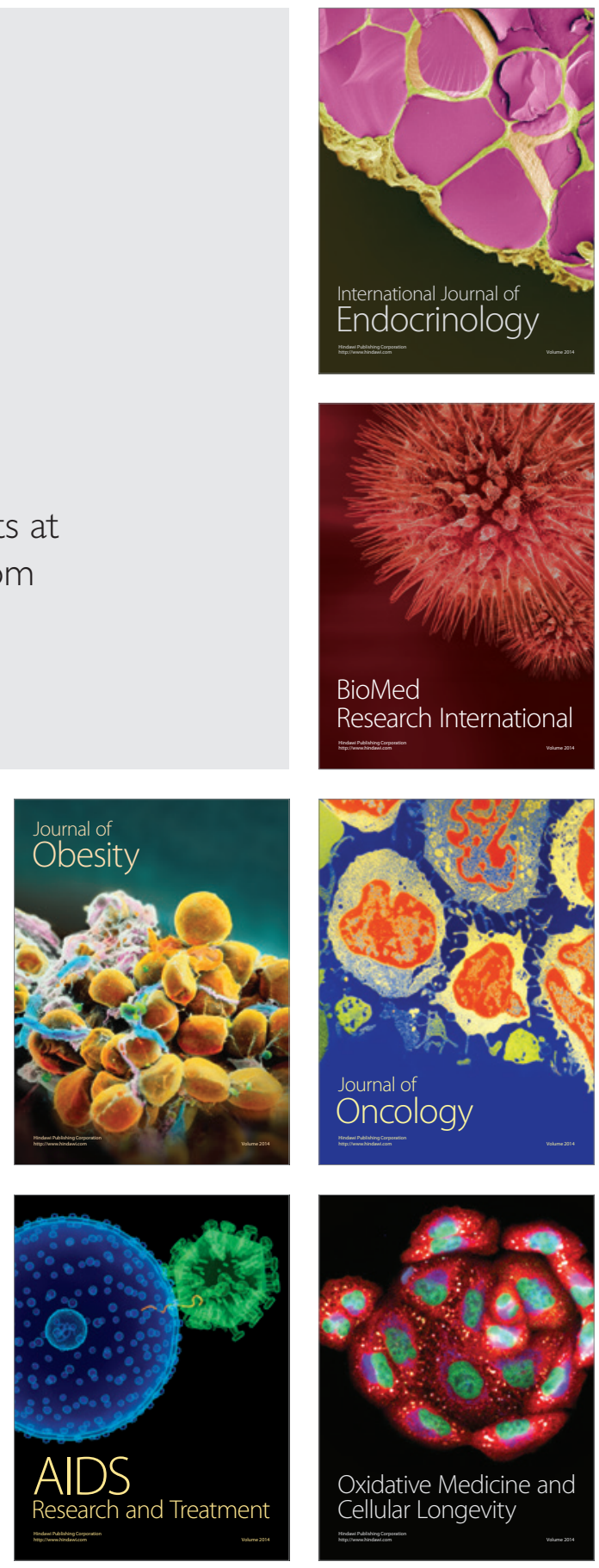